\title{
Bibliografía básica de Germán Colmenares
}

Por: Julián Galindo Zuluaga

Existen varios documentos sobre la vida y obra de Germán Colmenares. Un buen número de ellos están disponibles en línea. La presente bibliografía no pretende ser un recorrido exhaustivo por la producción bibliográfica del profesor Colmenares, pues aquella empresa es muy compleja. Así, acá se propondrán algunos de los artículos más llamativos de Colmenares, y las obras que tomaron cuerpo de libro, en clave del dossier que nos ocupa y sus líneas temáticas.

Antes de aquella tarea, es propicio mencionar someramente alguna documentación/repositorios a revisar si se quiere observar con más detenimiento la producción bibliográfica de Colmenares. En primer lugar, es menester aclarar que no existe texto alguno que contenga toda la vida y obra de Colmenares.

Siendo así, demos paso a algunos documentos valiosos. El primero de ellos, por su detenimiento y volumen, sería la separata de Hernán Lozano, editor de la llamada "Obra Completa" de Germán Colmenares; su identificación bibliográfica es: Lozano, Hernán. "Colmenares, un rastro de papel”. Historia y espacio [separata] n. ${ }^{\circ} 14$ (1991): 1-55. Otro trabajo que presenta no sólo un índice bibliográfico muy completo, sino también documentación sobre la historia intelectual y académica de Colmenares es la obra identificada como: Atehortúa Cruz, Adolfo León. Germán Colmenares. Una Nueva Historia. Cali: Universidad del Valle, 2013.

Posteriormente, si nos referimos a minucias y aspectos más personales del asunto, el trabajo se limitaría a una búsqueda personal. Sin lugar a duda, donde más trabajos se encuentran disponibles en línea es en el Boletín Cultural y Bibliográfico, donde hay una variada selección de textos que van desde el pensamiento político en el siglo XIX, hasta los jesuitas como empresarios. En menor cantidad, también encontramos en digital artículos de, sobre o que incluyen a Colmenares en Historia y espacio, el Anuario Colombiano de Historia Social y de la Cultura e Historia Crítica. Ahora, la documentación de acceso físico se incluye en revistas como Eco, Estravagario - Revista cultural del periódico El Pueblo-, y en una variada serie de periódicos, como El Espectador.

Mostramos, a continuación, nuestra selección, la cual se ciñe a las normas bibliográficas de citación Chicago. Los documentos que cuenten con un asterisco $\left(^{*}\right)$ indican que hacen parte de la "Obra Completa", e inmediatamente se ofrece el volumen ${ }^{1}$. Hay que llamar la atención sobre una errata, y es que se están citando las

1 Los tomos IX, X y XI corresponden a obras de publicación póstuma, tituladas, respectivamente: "Ensayos sobre historiografía", "Selección de textos", y "Ensayos sobre su obra". Los tomos del I-V hacen parte del subtítulo "Territorios y Ciudades"; del VI-IX, de "Crítica y Ensayo"; el X, de "Varios"; y, el XI, de "Homenaje a Germán Colmenares". 
primeras ediciones ${ }^{2}$ de las obras de Colmenares, anteriores a la edición de la "Obra Completa" de Hernán Lozano, por lo que en ocasiones la editorial y la fecha no corresponderán. El propósito de indicar la "Obra Completa" a priori se hace con motivos explicativos.

\section{Selección bibliográfica}

Colmenares, Germán. "Esquema para una Historia de las Ideas Políticas en Colombia durante el siglo XIX", tesis de pregrado, Universidad del Rosario, 19613.

—. Partidos políticos y clases sociales. Bogotá: Universidad de los Andes, 1968.* (T. $\mathrm{VI})$.

Colmenares, Germán; Margarita González y Darío Fajardo. Fuentes coloniales para la historia del trabajo en Colombia. Bogotá: Universidad de los Andes, 1968.

Colmenares, Germán. Las haciendas de los jesuitas en el Nuevo Reino de Granada. Bogotá: Universidad Nacional de Colombia, 1969.4* (T. IV).

-. Encomienda y población en la Provincia de Pamplona (1549-1650). Bogotá: Universidad de los Andes, 1969.

- La Provincia de Tunja en el Nuevo Reino de Granada: ensayo de historia social (1539-1800). Bogotá: Universidad de los Andes, 1970.* (T. V).

—. "Problemas de la estructuras minera en la Nueva Granada (1550-1700)". Anuario Colombiano de Historia Social y de la Cultura, n. ${ }^{\circ}$ 6-7 (1972): 5-56.

-. Historia económica y social de Colombia, 1537-1719. Cali: Universidad del Valle, $1973 .{ }^{5 *}$ (T. I).

—. Cali: terratenientes, mineros y comerciantes: siglo XVIII. Cali: Universidad del Valle, 1975.* (T. III).

2 Hay textos que tienen diversas ediciones. Por motivos prácticos, emplearemos la primera edición en todas las ocasiones.

3 Este texto fue la base de su primer libro (1968), que ya se mencionará.

4 Producto de su tesis de posgrado en la Universidad de Chile, aquel trabajo fue dirigido por el profesor Rolando Mellafe.

5 Es propicio agregar que dicho trabajo es considerado por muchos como la obra culmen del profesor Colmenares, los otros escritos de historia socioeconómica fueron laboratorios para lograr su magnus opum y se nota su influencia en la obra. 
—. "La economía y la sociedad coloniales, 1550-1800". En Manual de Historia de Colombia t. I, Jaime Jaramillo Uribe (ed.), 223-300. Bogotá: Instituto Colombiano de Cultura, 1978.

—. Historia económica y social de Colombia, t. 2. Cali: Universidad del Valle, 19796* (T. II).

- Ricardo Rendón. Una fuente para la historia de la opinión pública. Bogotá: Fondo de Cultura Cafetero, 1984.* (T. VIII).

—. "Los jesuitas: modelo de empresario coloniales". Boletín Cultural y Bibliográfico 21, n. ${ }^{\circ} 2$ (1984): 42-53.

—. "La nación y la historia regional en los países andinos, 1870-1930". Revista Andina 3, n. ${ }^{\circ} 2$ (1985): 311-3417.

—. Las convenciones contra la cultura. Bogotá: TM Editores, 1986.* (T. VII).

—. "La formación de la economía colonial (1500-1740)". En Historia económica de Colombia, José Antonio Ocampo (ed.), 13-47. Bogotá: Siglo XXI, 1987.

-. Relaciones e informes de los gobernantes de la Nueva Granada, tomo I. Bogotá: Banco Popular, 1989.

Ibid., tomo II.

Ibid., tomo III.

—. "La batalla de los manuales en Colombia". En Latinoamérica: Enseñanza de la Historia, Michael Rickenberg (comp.), 87-99. Buenos Aires: FLACSO, 1991 ${ }^{8}$.

- "La ley y el orden social: fundamento profano y fundamento divino". Boletín Cultural y Bibliográfico 27, n. ${ }^{\circ} 22$ (1990): 3-19.

- "El tránsito a sociedad campesinas de dos sociedad esclavistas en la Nueva Granada: Cartagena y Popayán, 1780-1850”. Huellas n. 29 (1990): 8-24.

6 También conocido/identificado como Popayán: una sociedad esclavista, 1680-1800.

7 Incluye once páginas con comentarios de diversos académicos.

8 La fecha de publicación original data de antes (1989), sin embargo, se ha escogido esta versión por encontrarse compilada. 
—. "El manejo ideológico de la ley en un periodo de transición". Historia Crítica n. ${ }^{\circ} 4$ (1990): 8-31.

-. "Historia, arte y sociedad en la Nueva Granada, siglo XVIII". Historia Crítica n. ${ }^{\circ} 4$ (1990): 31-42.

—. "Sin título". Historia Crítica n. ${ }^{\circ} 4$ (1990): 41-459.

9 Las tres últimas publicaciones, en Historia Crítica, se exhiben dentro de un homenaje presentado por Jaramillo Uribe titulado "Germán Colmenares y su obra". 